\title{
Remoto, mas não distante: a reinvenção do ensino na Educação Superior em tempos de COVID-19 1
}

\author{
Remote, but not far: the reinvention of teaching in Higher Education in \\ times of COVID-19
}

Carla Cristie de França Silva Doutoranda - Programa de Pós-Graduação em Psicologia. Universidade Católica de Brasília - UCB. Brasília, DF - Brasil. carlacristie@gmail.com

iD Lêda Gonçalves de Freitas Pós-Doutora - Professora Titular do Programa de Pós-Graduação em Psicologia. Universidade Católica de Brasília - UCB. Brasília, DF - Brasil. ledagfr@gmail.com

Resumo: O presente artigo tem como principal objetivo investigar quais foram os desafios e as soluções para se reinventar o ensino na Educação Superior frente ao cenário avassalador de contaminação pelo COVID-19, usando as Tecnologias Digitais da Informação e Comunicação (TDICs). Os dados foram coletados por meio de questionário eletrônico e entrevistas. A pesquisa contou com a participação de 41 estudantes. As informações foram sistematizadas e analisadas por meio da técnica de análise de conteúdo, proposta por Bardin (2010), possibilitando a identificação de três categorias: 1) Utilização das TDICs nos processos de ensino e aprendizagem, 2) Mediações pedagógicas necessárias ao desenvolvimento do estudante e 3) Autonomia discente. Os resultados revelaram que muitos estudantes subutilizavam as tecnologias digitais e que a pandemia oportunizou mudanças atitudinais. Aos docentes foi necessária a reinvenção das estratégias didáticas para o ensino remoto bem como a utilização das TDICs em espaços colaborativos que fomentaram nos discentes o protagonismo, o exercício da autonomia e a emancipação intelectual.

Palavras-chave: Educação Superior. Pandemia. Remoto. Reinvenção. Ensino e aprendizagem.

Abstract: This article aims to investigate what were the challenges and solutions to reinvent teaching in Higher Education, in the face of the overwhelming scenario of contamination by COVID-19, using Information and Communication Technologies (ICTs). Data were collected by an electronic questionnaire and interviews. The survey was answered by 41 students. The information was systematized and analyzed using the content analysis that was proposed by Bardin (2010), it is possible to identify three categories: 1) Application of ICTs in the teaching and learning processes, 2) Pedagogical mediations that were necessary for the students' development and 3) Students' autonomy. The results revealed that many students underutilized digital technologies and that the pandemic provided opportunities for attitudinal changes. Teachers had to reinvent didactic strategies for remote teaching, as well as the use of ICTs in collaborative spaces that fostered empowerment, autonomy and intellectual emancipation in the students.

Keywords: Higher Education. Pandemic. Remote. Reinvention. Teaching and learning.

\footnotetext{
1 Trata-se de um estudo realizado no projeto de doutorado do programa Stricto Sensu Doutorado em Psicologia da Universidade Católica de Brasília e aprovado pelo CEP, número do Parecer: 4.149.628.
} 


\section{Introdução}

Há alguns anos, as Tecnologias Digitais de Informação e Comunicação (TDICs) foram incorporadas aos espaços acadêmicos e científicos, ampliando a necessidade de uma educação dinâmica, coordenada por uma didática que propiciasse transformações pedagógicas e potencializasse o aprendizado híbrido. Nesse sentido, Castells (1999) destaca a necessidade de interação entre os diferentes contextos, ressaltando a importância da sociedade conectada e em rede. Mas, mesmo consciente desta responsabilidade, as instituições educacionais foram fragilizadas com o vírus SARS-CoV-2, responsável pela disseminação da pandemia do COVID-19, doença causada pelo novo Coronavírus, que se espalhou velozmente no ano de 2020 provocando milhares de mortes e uma crise global na educação.

O cenário global é desolador. As consequências da pandemia emergem as acentuadas diferenças econômicas e sociais nos países subdesenvolvidos, principalmente no Brasil, explicitando a fragilidade nas relações educacionais em todo o mundo. A Organização das Nações Unidas para a Educação, a Ciência e a Cultura (UNESCO), em um de seus pronunciamentos, enfatizou que a queda nas etapas de aprendizagem poderá alastrar-se por mais de uma década em todo o mundo, caso não sejam propostas políticas públicas capazes de garantir melhorias na infraestrutura, na formação, nas tecnologias e nas metodologias utilizadas por todos os envolvidos nas etapas de ensino e aprendizagem (UNESCO, 2020). Por esse motivo, é tão necessário utilizar as TDICs e demais dispositivos, sejam pessoais ou institucionais, para uma educação na perspectiva do desenvolvimento humano, científico e tecnológico, capaz de fomentar o protagonismo, o exercício da autonomia e a emancipação intelectual.

Desde o ano de 2005, as ações e intervenções propostas e realizadas por dispositivos móveis na educação para o desenvolvimento humano, científico e tecnológico no Brasil, são regulamentadas pelo Centro de Estudos sobre as Tecnologias da Informação e da Comunicação (Cetic.br), departamento do Núcleo de Informação e Coordenação do Ponto BR (Nic.br) que tem como propósito implementar as decisões e projetos do Comitê Gestor da Internet do Brasil (Cgi.br) e promover pesquisas capazes de contribuir para o desenvolvimento em potencial da internet no país. O portal do Centro Regional de Estudos para o Desenvolvimento da Sociedade da Informação - CETIC.br - revela, por meio de acompanhamentos periódicos que, desde o ano de 2010, os números de computadores de mesa vêm diminuindo e perdendo espaço para tablets, smarthphones e laptops, comprovando o aumento diário da utilização dos dispositivos móveis no país e a constituição de uma nova cultura tecnológica e digital (BRASIL, 2016). 
Com a disseminação dos celulares, tablets, smarthphones, laptops e demais tecnologias, no cotidiano acadêmico e científico, foi necessário, em tempos de pandemia, implementar ações com o propósito de reinventar os processos de ensino e aprendizagem, tornando-os cada vez mais híbridos, dinâmicos e colaborativos além de aprimorar a mediação pedagógica docente e estabelecer iniciativas as quais, segundo Belloni (2006) e Schön (2000), corroborassem com a consolidação de um profissional competente e multiqualificado que cotidianamente se propusesse a aprender a conhecer, aprender a fazer, aprender a conviver e aprender a ser (DELORS et al., 2010).

Ensino presencial, remoto e virtual são algumas das nomenclaturas e iniciativas mais usadas para se garantir as aprendizagens e o distanciamento social, sendo essas consideradas medidas mais recomendáveis para se evitar o contágio pelo Coronavírus. Atualmente, o mercado brasileiro de TDICs conta com soluções robustas e plataformas digitais multifuncionais as quais podem contribuir com a organização do trabalho pedagógico e os processos de ensinagem. Ressalta-se a ensinagem como uma prática social, crítica e complexa em educação efetivada entre os sujeitos "englobando tanto a ação de ensinar quanto a de apreender" (ANASTASIOU; PESSATE, 2012, p. 20).

Sabe-se que o sistema educacional brasileiro tem sofrido com os impactos da pandemia do Coronavírus. São mais de 54 milhões de estudantes da Educação Básica à Educação Superior, segundo monitoramento realizado pelo Vozes da Educação (2020), com rotinas indefinidas e aulas paralisadas em algumas ocasiões realizadas remotamente devido à pandemia do COVID-19. Assim, torna-se imprescindível que o poder público e as instituições de ensino, mesmo frente a tantas incertezas, se reorganizem para encontrar alternativas a fim de garantir que o processo de ensino e aprendizagem continue acontecendo, mesmo fora das convencionais quatro paredes.

Considerando o cenário em vigor, o docente indubitavelmente, frente à pandemia do COVID-19, terá o papel de articular, mediar e promover ações de interatividade e aprendizagem principalmente ressignificando a utilização das TDICs e tornando tais recursos mais usuais e atrativos para alcançar o desenvolvimento de habilidades e competências condizentes à Educação Superior. Nesse contexto, reafirma-se a relevância deste artigo que se propõe a elucidar quais foram os desafios e as soluções para se reinventar o ensino na Educação Superior frente ao cenário avassalador de contaminação pelo COVID-19 com o uso das TDICs.

Metodologicamente, esta pesquisa fundamenta-se na abordagem qualitativa. Segundo Mayring (2002), esse tipo de pesquisa exige atenção e cuidado quanto às etapas de: a) delineamento, b) coleta de dados, c) transcrição e d) preparação dos dados para a respectiva análise, posto que os 
dados coletados explicitam significados, subjetividades e expressam a compreensão de processos que ocorrem nas inter-relações e nas dinâmicas mais complexas, possibilitando ao pesquisador iniciativas capazes de contribuir com a percepção de nuances para dar sentido e significado às realidades investigadas por meio de um processo analítico e interpretativo acerca das evidências apresentadas (GONZÁLEZ-REY, 2002). De natureza exploratória descritiva, a pesquisa tem como propósito identificar e conhecer os atributos de uma determinada população aos quais os objetivos se propuseram, dado que a disseminação da temática investigada é relevante e significativa (GIL, 2008).

Assim, após a emissão do parecer de aprovação do Comitê de Ética em Pesquisa com Seres Humanos de $n^{\circ}$ 4.149.628, foi iniciada a investigação em uma Instituição de Educação Superior (IES), localizada no Distrito Federal. Contribuíram 41 universitários, da modalidade de ensino presencial, maiores de 18 anos. O grupo constituía-se por estudantes dos cursos de: Ciência da Computação com 13 participantes, Análise e Desenvolvimento de Sistemas com 5 participantes, Jornalismo, Bacharelando e Licenciando em Química com 4 participantes cada, Comunicação Social (Publicidade e Propaganda), Engenharia de Software, Bacharelando em Física com 3 participantes cada, Licenciando em Física 2 participantes, não havendo, pois, nenhuma adesão nos cursos de Gestão da Tecnologia da Informação, Redes de Computadores e Sistemas de Informação.

A execução das etapas propostas na pesquisa passou por uma minuciosa análise, possibilitando acesso a informações relevantes do contexto investigado. Por meio da técnica de análise de conteúdo, proposta por Bardin (2010), foram criadas as seguintes categorias de análise e organização dos dados: 1) Utilização das TDICs nos processos de ensino e aprendizagem, 2) Mediações pedagógicas necessárias ao desenvolvimento do estudante e 3) Autonomia discente.

\section{Fundamentação teórica}

Diante de tempos de incertezas e pandemia do SARS-CoV-2, onde a sociedade emergente encontra-se em plena crise com "[...] milhões de desempregados, dias de fome, cidades decadentes, hospitais superlotados, administrações enfermas, explosões de violência, ideologia de austeridade, discursos fátuos, revoltas populares, novas estratégias políticas, esperanças, medos [...]” (APPLE, 1989, p. 19), é necessário atentar-se para que as tecnologias e os meios de comunicação e a própria cultura não sejam minimizados e utilizados convenientemente a favor de uma concepção capitalista neoliberal, dicotômica e esclerosada, comprometendo as relações de aprendizagem e de desenvolvimento humano e social (PALANGANA, 1998). Por isso, é imprescindível estar atento 
à ampliação da inovação disruptiva para que as TDICs não sejam manipuladas e entregues à voracidade do mercado.

Presentes em diferentes espaços contemporâneos, as TDICs corroboram com o surgimento de processos de aprendizagem pouco lineares, mas que, no entanto, promovem estímulos como a neuroplasticidade e as condições para o desenvolvimento das funções do córtex cerebral. Sabe-se que o córtex cerebral possui funções distintas, divididas por áreas específicas para a execução dos sentidos, da atenção e da memória assim como por áreas responsáveis pelo pensamento e consciência. Quando o cérebro se encontra em situação de aprendizagem, ocorrem macro e micro transformações neuronais que funcionam como uma espécie de criação de circuitos, promovendo uma eficiente velocidade de transmissão e precisão conexiva para garantir o fortalecimento de sinapses, redes e sistemas neurofuncionais para se apreender (AMARAL; NOGUEIRA; FERREIRA, 2017).

No entanto, para que as novas conjunturas de apreender e ensinar ocorram, nas práticas e no cotidiano da educação superior, é imprescindível que a cultura e os currículos propostos sejam atualizados priorizando as interações sociais onde, segundo Vygotsky (1984), o desenvolvimento humano ocorre promovendo estímulos e novas sinapses que, por sua vez, fomentam uma relação onde o ser humano se constrói e reconstrói biologicamente, culturalmente e historicamente, patenteando o papel da comunicação, da linguagem e do processo histórico-social no desenvolvimento do indivíduo. Ressalta-se que o aprendizado e o desenvolvimento são processos intercadentes se relacionam permanentemente, potencializam a formação de ideias, passando pelas funções psicológicas superiores onde o conhecimento é constituído por meio de trocas realizadas consigo, com o outro e com o meio.

Tal meio constitui-se pelo conjunto de objetos, aparatos e instrumentos com os quais ocorrem transformações, considerando aspectos físicos, socioculturais e afetivos, possibilitando assim a constituição de novas aprendizagens. Portanto, pensar em utilizar as TDICs somente instrumentalmente é minimizar uma potência, daí a necessidade de explorá-las a partir de eixos estruturantes como elementos estratégicos, promovendo o trabalho colaborativo e estabelecendo uma economia em rede, entrelaçada com o desenvolvimento e tecida por grandes interesses.

Para se ter uma cultura colaborativa e uma economia para o desenvolvimento, torna-se imprescindível o olhar crítico e a ruptura com uma educação superficial e reprodutivista. É, pois, a partir da abordagem da Psicologia Histórico-Cultural e da Pedagogia Histórico-Crítica que é possível propor uma autonomia libertária a qual permita ir além do desenvolvimento pessoal o social, priorizando o exercício da cidadania, o protagonismo e a criatividade. Atributos esses 
primordiais à Educação Superior que contribua com grandes transformações de modo a imergir no universo da autonomia, de cidadania, de lógica, de jeito, de aprender, de saber cuidar, inovar e acreditar, conforme aponta Demo (2005, p.13), para a necessidade de "termos o cuidado da construção desta autonomia, dessa cidadania tão necessária à democratização da sociedade brasileira". Desde a promulgação da Constituição da República Federativa do Brasil (BRASIL, 1988), tinha-se como propósito uma educação a serviço do pleno desenvolvimento da pessoa humana, seu preparo para o exercício da cidadania e a qualificação profissional. Porém, somente com a Constituição, não foi possível garantir o exercício dos direitos propostos. Desta forma, com a Lei de Diretrizes e Bases da Educação Nacional de 1996 (BRASIL, 1996), a união propôs uma espécie de pacto interfederativo que se trata de um acordo com diversos níveis de governo para o estabelecimento de competências e diretrizes, capazes de orientar os currículos e consolidar propostas.

Assim, com o Plano Nacional de Educação (PNE), Lei no 13.005/2014 (BRASIL, 2014), proposto para o período de 2014 a 2024, estão definidos os objetivos e metas para o ensino em todos os níveis, básico, desde a educação infantil até a Educação Superior, a serem executados nos próximos dez anos. Desse modo, o PNE, apresentado como Lei, deixa de ser uma mera carta de intenções para ser apresentada como um rol de obrigações, passando a ser imperativo legal para o setor público (SILVA, 2001).

As exigências propostas no PNE relacionam-se e resultam em necessidades que se desdobram em expectativas de aprendizagem nos campos de experiência da Educação Infantil à Educação Superior. Para tanto, propõe vinte metas que priorizam diretrizes e estratégias da Educação Básica à Educação Superior nas quais podem se destacar e relacionar considerando os aspectos relevantes aos quais se dispõem nas metas 9 e 12 do referido documento:

A Meta 9, intitulada "Alfabetização e alfabetismo funcional de jovens e adultos", destaca a necessidade do exercício do protagonismo, da autonomia e criatividade, visto que, no momento atual, necessita-se de um indivíduo não somente alfabetizado, mas autônomo e protagonista para fomentar novas iniciativas, propondo-se a realizar ações colaborativas e criativas, possibilitando a resolução dos problemas presentes na sociedade e promovendo a sua própria emancipação. Em consonância a esta meta, Perrenoud (1999, p. 96) enfatiza que "toda ação educativa só pode estimular o autodesenvolvimento, a autoaprendizagem, a autorregulação de um sujeito, modificando seu meio e entrando em interação com ele".

Já a Meta 12, destinada à Educação Superior, destaca ser imprescindível que esse nível de ensino seja constituído para além do acesso e da ampliação da escolaridade. Como proposto na 
Psicologia Histórico-Cultural, torna-se necessário que as relações aprendizagem-desenvolvimento, linguagem-pensamento e afeto-cognição possibilitem que os sujeitos passem da função psicológica elementar - memória, inteligência emocional, sensações - para o pensamento psicológico superior, que opera a partir de processos complexos do pensamento - memória voluntária, afetividade e o pensamento abstrato que contribuem para a compreensão de diversos aspectos da realidade e personalidade humana (VYGOTSKY, 1984).

Estudos realizados por Vygotsky (1984) enfatizam que existem dois elementos indispensáveis para o processo mediativo: os instrumentos e os signos. Os instrumentos são materiais os quais fazem a mediação por meio das ferramentas e das TDICs que dinamizam o cotidiano do indivíduo. Os signos, por sua vez, medeiam e auxiliam as relações entre homem e objeto em tudo que se refere a atitudes, pensamentos, sentimentos e ao controle das atividades psicológicas. Uma das principais conquistas da abordagem vigotskiana é o reconhecimento do signo como elemento indispensável na relação do homem com o mundo. A relação do homem com o mundo e a consolidação da "essência humana" são mediadas de forma peculiar, definindo limites, possibilidades, ações e intercessões. Na perspectiva histórico-cultural, considera-se que o homem é um ser dotado de cultura e de história o qual vivencia permanentemente o processo interativo-mediatizado-mediador, de síncrese-análise-síntese, de apropriação, interação e produção na sociedade pertencente, provocando, pois, a necessidade de adaptação ao período pandêmico com ações, reflexões e problematizações paralelas a uma educação para a autonomia.

\section{Discussão e análise dos dados}

A pesquisa revela que os participantes do estudo são adultos jovens: 46,3\% possuem entre 18 e 20, 51,2\% entre 21 e 29 anos e 2,4\% entre 30 e 39 anos de idade. Como os cursos pesquisados são predominantemente da área de exatas, ainda existe um maior percentual de matriculados do gênero masculino, totalizando $61 \%$ enquanto o público feminino tem a representação de 39\%.

Quanto à categoria 'Utilização das TDICs nos processos de ensino e aprendizagem', percebe-se que, ao serem indagados sobre o tempo que utilizam as tecnologias digitais no cotidiano, 24,4\% dos estudantes mencionaram ficar conectados menos de seis horas diárias, 46,3\% dos participantes pelo menos seis horas diárias e 29,3\% acima de doze horas diárias conectados à Internet. Pode-se enfatizar a relação de que quanto mais jovem o sujeito pesquisado maior a proporção de conexão e imersão no universo digital. Os dados evidenciam que a integração com as hipermídias, as redes sociais e o universo da comunicação e a cultura digital são instrumentos imprescindíveis para relacionar-se com o mundo e com as novas formas de se comunicar e 
apreender. Canclini (2006) assevera que as mídias podem ser compreendidas como processos de desenvolvimento e aprendizagem nos espaços de cultura digital, impactando diretamente na formação da subjetividade de cada sujeito. Assim, o educador é convidado a repensar sua prática docente e integrá-la à cultura digital, tecendo parcerias e adaptando-se aos cenários híbridos de aprendizagem e ensino.

Os sujeitos pesquisados relatam que frequentemente participam das aulas remotas e demais atividades acadêmicas. Durante a pandemia, 90,2\% afirmam utilizar o computador em casa, 46,3\% fazem uso do smartphone em casa e 14,6\% usam o computador no trabalho para realizar as atividades acadêmicas propostas. O fato é que embora se perceba o aumento no uso do smartphone, não necessariamente esse aumento determina o pleno aproveitamento desse equipamento dado que os computadores de mesa, apesar de estarem "fora de moda" e mais caros, possibilitam a realização de atividades que exigem maior complexidade e capacidade analítica, inclusive com mais conforto e comodidade. Como estão fixos, convencionalmente conectados em banda larga, apresentam maior velocidade de conexão e tráfego de dados. O interessante é que, justamente nos segmentos socioeconômicos de ampla vulnerabilidade social, é observada expansão das redes de acesso à Internet, exclusivamente pelo telefone celular.

Kozulin (2000) destaca que existem muitas expectativas sobre as potencialidades educacionais das TDICs, pois são como instrumentos psicológicos no sentido vygotskyano que defende as ferramentas tecnológicas, que quando pedagogicamente mediadas, estimulam o pensar, o sentir e o agir sozinho ou colaborativamente. Tal afirmação se apoia na natureza simbólica das tecnologias que, segundo Coll e Monereo (2010, p. 76), "permitem criar ambientes os quais integram os sistemas semióticos conhecidos e ampliam até limites inimagináveis a capacidade humana de (re)apresentar, processar, transmitir e compartilhar grandes quantidades de informação".

Na categoria 'Mediações pedagógicas necessárias ao desenvolvimento do estudante', percebe-se que foi exigido do docente uma maior interlocução com os estudantes, criando atividades que demandavam proatividade, interação, troca, reflexão, análise, provocando-os ao exercício da autonomia e ao exercício do saber fazer.

Aos docentes tornou-se indispensável a utilização de procedimentos metodológicos sistematizados, integradores e inovadores tais como: aplicativos, plataformas digitais e ambientes virtuais que potencializassem a qualidade das relações de aprendizagem. É importante ressaltar que as mediações pedagógicas, propostas pelos docentes, tiveram como intencionalidade desenvolver as funções psíquicas superiores, tais como: a atenção voluntária, o pensamento conceitual, a 
memória lógica, o controle do comportamento para que assim fosse possível promover a aprendizagem e o desenvolvimento do estudante, mesmo em tempos de pandemia.

O docente precisa estar adequadamente preparado e instrumentalizado quanto à formação, à intencionalidade pedagógica, à proposta curricular e à motivação do estudante em aprender. Assim, a aprendizagem tornar-se-á relevante ao promover a aprendizagem a partir de problematizações e socializações realizadas entre aluno-professor, aluno-aluno, aluno-conteúdo num processo dinâmico onde professor e estudante são sujeitos ativos do aprender-ensinar. Por isso, é imprescindível utilizar as TDICs com o propósito de subsidiar estratégias e elaborar atividades fomentadoras ao desenvolvimento de novas formações psíquicas. Assim, ressalta-se que, sem a possibilidade de convivência, encontro e interatividade, não há aprendizagem (MATURANA,1993) como podem ser analiticamente abrangidos a partir dos relatos:

\footnotetext{
"Aprendi bastante coisa nesse período de pandemia, pois não tinha conhecimento da maioria dos recursos, porém o professor deixou a tarefa e acreditei seria importante realizá-la para garantir o meu desempenho e aprendizagem de conteúdo. Fui e corri para aprender".

"Usei também bastante o Whats App, porque converso muito com os meus amigos e colegas de aulas e vamos tirando dúvidas... A gente fazia muito isso lá em nosso laboratório de informática presencial, ficava todo mundo lá, mexendo e se ajudando...”. "Aprendi muito porque busquei com amigos e colegas da turma".

"Usei muito os recursos Google for Education, Moodle... A gente usava muito o Discord". É um aplicativo como Whats App para alunos de TI (Tecnologia da Informação) só que compartilhando o que se faz".
}

As assertivas retratam que a ação pedagógica docente na contemporaneidade deve também fundamentar-se em instigar o estudante e estabelecer uma teia de relações interdependentes onde a iniciativa contribua para a (des)construção de modelos e enfatize a perspectiva de seres inconclusos à medida que as relações colaborativas e sociais permitam condições legítimas para novas perspectivas de desenvolvimento e aprendizagens (FREIRE,1983). Belloni (2006) alerta que o uso descontextualizado das tecnologias corresponde a uma iniciativa tecnicista, redutora do processo de aprendizagem. Assim, é preciso direcionar o trabalho do professor e permitir múltiplos espaços para socialização de experiências e compreensão dos processos pedagógicos para que seja possível fomentar iniciativas necessárias à aprendizagem significativa.

$\mathrm{Na}$ categoria 'Autonomia discente', ao serem questionados quanto à importância da autonomia, os resultados revelaram que muitos estudantes subutilizavam as tecnologias digitais e que a pandemia oportunizou mudanças atitudinais. Aos docentes foi necessária a reinvenção das estratégias didáticas para o ensino remoto assim como a apropriação para o uso das TDICs em espaços colaborativos que fomentassem nos discentes o protagonismo e a emancipação intelectual como se observou nos excertos: 


\begin{abstract}
"O professor sempre falava que estava cheio de e-mail para responder. Assim se tivesse dúvidas e fosse enviada por e-mail teria de esperar. Enfatizava: Posso demorar um pouco, mas responderei assim que possível. Tinha então que participar do ambiente virtual para ter uma resposta mais rápida. E muitas vezes era um colega e mais outro que respondia primeiro, depois o professor. Isso era bom porque nos forçava a resolver as coisas e aprender junto em vez de ficar esperando a resposta do professor. Isso é autonomia, né? Correr atrás..."
\end{abstract}

Os pesquisados evidenciam a educação autônoma, criadora, metacognitiva e problematizadora assim proposta por Freire (2011), exigindo ações que possibilitam aprendizagens. Nessa mesma direção, Belloni (2006, p.39) destaca que "um processo de ensino e aprendizagem deve ser centrado no aprendente [...], permitindo-lhe ser gestor de seu processo de aprendizagem, capaz de autodirigir e autorregular esse processo". Implicitamente, as plataformas, os aplicativos e os ambientes virtuais, quando adequadamente mediados, podem favorecer significativamente o desenvolvimento humano, ampliando os espaços e as relações de saber como expressa o estudante:

\footnotetext{
"Acredito que tenha sido um pouco difícil pois prefiro muito mais a sala de aula do presencial, prefiro o olho no olho, para conversar com o professor, mas tenho me adaptado. Tenho procurado as ferramentas instantâneas como o Whats App lá a conversa é intensa. Coloco uma pergunta e as respostas chegam bem mais rápido. A gente vai se ajudando e se acostumando com os novos espaços para se aprender".
}

Por isso, dada a importância das relações de interatividade e mediação presentes nos ambientes digitais nos quais, sobretudo por meio dos diálogos e intervenções, é possível estabelecer e exercitar o movimento do pensamento fundamentado na síncrese, na síntese e na análise, buscando um resultado mais colaborativo, elaborado, emancipado e autônomo.

\footnotetext{
"A pandemia de COVID 19 me fez usar os recursos que mais tenho domínio: tablets e smarthphones são como parte do meu corpo. Não senti dificuldades durante as aulas remotas. Mas percebi que o professor sentia um pouco de receio ao propor alguns recursos pois havia colegas que não tinham nem conexão de internet adequada para realizar as tarefas".
}

Quando o educador optar por utilizar as TDICs, precisa compreender que nem todos os estudantes terão o mesmo comprometimento e, portanto, o mesmo desempenho, visto que possuem processos psicológicos superiores e estilos de aprendizagem são distintos, considerando o contexto social e cultural no qual se encontram inseridos. Assim, é preciso sensibilizá-lo para que pela mediação tais estudantes vivenciem novas experiências e tarefas, apropriando-se dos desafios e, consequentemente, de novas aprendizagens e de novos conhecimentos. 


\section{Considerações finais}

O presente estudo se propôs a investigar quais foram os desafios e soluções, frente ao cenário avassalador de contaminação pelo COVID-19, para reinvenção necessária do processo de ensino-aprendizagem na Educação Superior a partir do uso das Tecnologias Digitais da Informação e Comunicação (TDICs).

A pandemia tem impactado no comportamento de estudantes e docentes com as mudanças pedagógicas. A pesquisa evidencia que os desafios para se manter a qualidade da aprendizagem na Educação Superior foram abruptas mudanças que exigiram práticas imediatas diferenciadas tanto de docentes como discentes. Percebe-se a partir dos relatos que alguns jovens não tinham sequer acesso a dispositivos ou à Internet, dificultando a uniformidade das atividades propostas. É possível perceber que a maioria dos jovens estudantes está hiperconectada, por meio das TDICs, mas precisam ser provocados a saírem da zona de conforto e se apropriarem de novas ferramentas e possibilidades pedagógicas para apreender conteúdos curriculares.

Os relatos dos universitários evidenciam que as mudanças ocorridas no cotidiano acadêmico, devido à pandemia do COVID-19, foram diversas, impactando na práxis, tornando-se perceptível a necessidade de aprimoramento na formação pedagógica docente para utilização adequada das TDICs.

As IESs, por meio de seus docentes e propostas, precisam lançar-se aos desafios e investir em uma formação permanente, uma cultura tecnológica e digital no âmbito colaborativo, progressista e que, concomitantemente, impulsionem o discente ao exercício da curiosidade e do interesse, conduzindo-os a situações problematizadoras e desafiando-os à ruptura de paradigmas e à imersão em atividades significativas, oportunizando, pois, a cada estudante potencializar a sua própria aprendizagem.

Em tempos de pandemia do COVID-19, o ensino e as aprendizagens podem continuar remotamente mas não distantes, visto que se faz necessário encontrar alternativas para atender aos diversos contextos e públicos, onde estudantes de baixa renda, que não possuem os recursos necessários, possam reinventar-se e igualmente aprender, além de contribuir para a efetivação de um ensino consolidado, híbrido. Desse modo, dar-se-á origem a novas experiências e espaços para a interatividade, diálogos, trocas e apropriação do conhecimento científico, provocando o surgimento de ações pedagógicas que potencializem a concepção reflexiva, emancipadora, autônoma e crítica para se apreender, mesmo em tempos complexos e de adversidades. 


\section{Dialogia}

SILVA, Carla Cristie de França; FREITAS, Lêda Gonçalves de. Remoto, mas não distante: a reinvenção do ensino na

\section{Referências}

AMARAL, I.; NOGUEIRA, M. I.; FERREIRA, F. R. M. Entre neurônios e sinapses: as contribuições de Cajal e Athias para a medicina ibérica entre os séculos XIX e XX. História, Ciências, Saúde-Manguinhos, Rio de Janeiro, v. 24, n. 1, p. 187-199, jan. 2017. Disponível em: http://www.scielo.br/scielo.php?script=sci_arttext\&pid=S0104-

59702017000100187\&lng=en\&nrm=iso. Acesso em: 10 maio 2019.

ANASTASIOU, L. das G. C.; PESSATE, L. Processos de ensinagem na Universidade. 10. ed. Joinville: Univille, 2012.

APPLE, M. W. Educação e poder. 2. ed. Porto Alegre: Artes Médicas, 1989.

BARDIN, L. Análise de conteúdo. 4. ed. Lisboa: Edições70, 2010.

BELLONI, M. L. Educação a distância. Campinas: Autores Associados, 2006.

BRASIL. Constituição da República Federativa do Brasil. Brasília: Senado Federal, Centro Gráfico, 1988.

BRASIL. Lei ñ 13.005, de 25 de junho de 2014, que aprova o Plano Nacional de Educação (PNE). Brasília: Câmara dos Deputados, 2014. Disponível em: http://www.observatoriodopne.org.br/uploads/reference/file/439/documento-referencia.pdf. Acesso em: 10 out. 2020.

BRASIL. Lei de Diretrizes e Bases da Educação Nacional. Lei número 9394, 20 de dezembro de 1996. Disponível em:

http://www2.senado.leg.br/bdsf/bitstream/handle/id/529732/lei_de_diretrizes_e_bases_1ed.p df. Acesso em: 20 maio 2020.

BRASIL. TIC Educação 2015: apresentação dos principais resultados. São Paulo: Centro de estudos sobre as tecnologias da informação e da comunicação, 2016. Disponível em: http://cetic.br/media/analises/tic_educacao_2015_coletiva_de_imprensa.pdf. Acesso em: 10 maio 2020 .

CANCLINI, N. G. Consumidores e cidadãos: conflitos multiculturais da globalização. 6. ed. Rio de Janeiro: UFRJ, 2006.

CASTELLS, M. A sociedade em rede. São Paulo: Paz e Terra, 1999.

COLL, C.; MONEREO, C. (orgs.). Psicologia da educação virtual: aprender e ensinar com as tecnologias da informação e da comunicação. Porto Alegre: Artmed, 2010.

DELORS, Jacques et al (Orgs.). Educação: um tesouro a descobrir. Brasília: Unesco, 2010.

DEMO, P. A educação do futuro e o futuro da educação. Campinas: Autores Associados, 2005.

FREIRE, P. Extensão ou comunicação? Rio de Janeiro: Paz e Terra, 1983.

FREIRE, P. Pedagogia da autonomia: saberes necessários à prática educativa. São Paulo: Paz e Terra, 2011. 


\section{Dialogia}

SILVA, Carla Cristie de França; FREITAS, Lêda Gonçalves de. Remoto, mas não distante: a reinvenção do ensino na Educação Superior em tempos de COVID-19

GIL, A. C. Como elaborar projetos de pesquisa. 5. ed. São Paulo: Atlas, 2008.

GONZÁLEZ-REY, F. L. Pesquisa qualitativa em psicologia: caminhos e desafios. São Paulo: Pioneira Thomson Learning, 2002.

KOZULIN, A. Instrumentos psicológicos: la educación desde una perspectiva sociocultural. Barcelona: Paidós, 2000.

MATURANA, H. Uma nova concepção de aprendizagem. Dois Pontos, Curitiba, v. 2, n.15, 1993. Disponível em https://ead-tec.furg.br/images/textos/uma_nova_concepcao_aprendizagem.pdf. Acesso em: 26 set. 2020.

MAYRING, P. Análise qualitativa de conteúdo: instrumento de pesquisa ou modo de interpretação? In. KIEGELMANN, M. (Ed.). O papel do pesquisador em psicologia qualitativa. Tuebingen: Verlag Ingeborg Huber, 2002, p. 139-148.

PALANGANA, I. C. Individualidade: afirmação e negação na sociedade capitalista. São Paulo: Plexus, 1998.

PERRENOUD, P. Avaliação: da excelência à regulação das aprendizagens - entre duas lógicas. Porto Alegre: Artmed, 1999.

SILVA, J. A. da. Curso de direito constitucional positivo. 19. ed. São Paulo: Malheiros, 2001.

SCHÖN, D. A. Educando o profissional reflexivo: um novo design para o ensino e a aprendizagem. Porto Alegre: Artmed, 2000.

UNESCO. A Comissão Futuros da Educação da Unesco apela ao planejamento antecipado contra o aumento das desigualdades após a COVID-19. Paris: Unesco, 2020. Disponível em:

https://pt.unesco.org/news/comissao-futuros-da-educacao-da-unesco-apela-aoplanejamento-antecipado-o-aumento-das. Acesso em: 04 jun. 2020.

VOZES DA EDUCAÇÃO. Educação e Coronavirus: levantamento das respostas de órgãos federais e estaduais à pandemia do Coronavírus no âmbito da educação básica. Brasil: Instituto Unibanco, Mapa Educação, Conselho Nacional de Juventude, 2020. Disponível em: http:/ / educacaoecoronavirus.com.br. Acesso em 22 dez. 2020

VYGOTSKY, L. S. A formação social da mente: o desenvolvimento dos processos psicológicos superiores. São Paulo: Martins Fontes, 1984.

Recebido em: 30 nov. 2020/ Aprovado em: 07 dez. 2020

Cite como

(ABNT NBR 6023:2018)

SILVA, Carla Cristie de França; FREITAS, Lêda Gonçalves de. Remoto, mas não distante: a reinvenção do ensino na Educação Superior em tempos de COVID-19. Dialogia, São Paulo, n. 36, p. 382-395, set./dez. 2020. Disponível em: https://doi.org/10.5585/dialogia.n36.18828. 


\section{Dialogia}

SILVA, Carla Cristie de França; FREITAS, Lêda Gonçalves de. Remoto, mas não distante: a reinvenção do ensino na Educação Superior em tempos de COVID-19

\section{American Psychological Association (APA)}

Silva, C. C. de F., Freitas, L. G. (2020, set./dez.). Remoto, mas não distante: a reinvenção do ensino na Educação Superior em tempos de COVID-19. Dialogia, São Paulo, 36, p. 382-395.

https://doi.org/10.5585/dialogia.n36.18828. 